Special Issue of the 8th International Advances in Applied Physics and Materials Science Congress (APMAS 2018)

\title{
Attenuation Gamma Rays Properties of Cement Paste-Waste Paper Composites
}

\begin{abstract}
A. KAÇAR ${ }^{a, *}$ AND D. TÜRKÖZ AltuĞ $\breve{G}^{b}$
${ }^{a}$ Süleyman Demirel University, Faculty of Technology, Department of Civil Engineering, Isparta, Turkey

${ }^{b}$ Süleyman Demirel University, Vocational School of Health Services, East Campus, 32260, Isparta, Turkey

In this study, cement composites were produced with CEN reference sand, cement, water, and waste paper. Waste paper were used as partial replacement 0-0.50 ratios of sand weight which was tagged as CK and WPCK, and the cement-to-sand ratio was kept constant at 1:3. Mix design was based on the standard of TS EN 196-1. The infrared spectra were recorded by accumulating 64 scans each in $4000-400 \mathrm{~cm}^{-1}$ range with a resolution of $4 \mathrm{~cm}^{-1}$ with $\mathrm{KBr}$ pellets at room temperature. The linear attenuation coefficients of composites were measured using the gamma spectrometer system containing $\mathrm{NaI}(\mathrm{Tl})$ detector. The measurements were performed at 1173 and $1332 \mathrm{keV}$, which was obtained from ${ }^{60} \mathrm{Co}$ radioactive sources.
\end{abstract}

DOI: 10.12693/APhysPolA.135.607

PACS/topics: recycling of waste paper, cement mortar, attenuation of $\gamma$-rays, sustainability, FTIR

\section{Introduction}

Technologies have brought many benefits to the world. Along with these benefits, some problems have arisen, one of which is the disposal of solid waste materials. Approximately $60 \%$ of the volume of solid waste in an average municipal waste stream consists of agro-based resources such as paper and paper-based products [1]. Developing new cement-based materials named composites have better physical, mechanical properties, and also radiation shielding properties which are important for both medical and nuclear power structures [2]. Although, in comparison to other construction materials used in nuclear reactors, concrete has many advantages when it is utilized as a radiation shield. A set of conflicting requirements must be met in the selection of ingredients and mix proportions of concrete designed for the optimum attenuation of both gamma and neutron radiation [3]. In recent years, it has become widespread that various waste materials are used for various purposes in civil engineering as concrete aggregate and cement added material. Composites that have been produced with wastes are very suitable for sustainability and it provides economic and environmental benefits, especially, for applications in building materials, as well as radiation shielding application. The initial benefits of using waste paper as additives in cement composites are: low density, low cost, and low energy consumption [4]. In this study, cement based composites with waste paper were produced which were tagged as CK and WPCK. The linear attenuation coefficients of composites were performed from ${ }^{60} \mathrm{Co}$ radioactive sources.

*corresponding author; e-mail: aysekacar@sdu.edu.tr

\section{Experimental procedure}

The composites have been produced using Portland Cement (PC) 42.5 type of cement from Goltas plant in Isparta. CEN reference sand is used as fine aggregate in this research. CEN reference sand is natural and siliceous sand consists preferably of rounded particles and has a silica content of at least $98 \%$. The paper waste used in this study was collected from some copy centre in Isparta city. Dried paper waste was soaked in water for $24 \mathrm{~h}$ and was mixed by mechanical means to attain paper pulp. Paper pulp has irregular pores and fibrous nature, and holds the moisture in these pores. Moreover, this fibrous nature gives very high energy absorbing ability and hence, high compressive strength [5]. City network water was used as mixing water. The measurements were performed at 1173 and $1332 \mathrm{keV}$ which was obtained from ${ }^{60} \mathrm{Co}$ radioactive sources. The photon attenuation coefficients have been evaluated comparing $I$ and $I_{0}$. The $I_{0}$ denotes the photons intensity with energy, without attenuation and $I$ is the photons with energy after attenuation; $\mu\left(\mathrm{cm}^{-1}\right)$ is the attenuation coefficient and $x(\mathrm{~cm})$ is the sample thickness and the attenuation coefficient is calculated using the Beer-Lambert equation below [6]:

$$
I=I_{0} \mathrm{e}^{-\mu x} \text {. }
$$

\subsection{Infrared analysis (FTIR)}

The main equipment used was Spectrum BX FT-IR spectrometer system (Perkin Elmer). The infrared spectra were recorded by accumulating 64 scans each in $4000-400 \mathrm{~cm}^{-1}$ range with a resolution of $4 \mathrm{~cm}^{-1}$ with $\mathrm{KBr}$ pellets at room temperature.

\section{Results and discussion}

When $\mathrm{Si}-\mathrm{Ph}$ (with phenyl group) is in-plane bending vibration, at $692 \mathrm{~cm}^{-1}[7,8]$ for CK it appears as the small bond. This is weakly observed for WPCK in Fig. 1. 


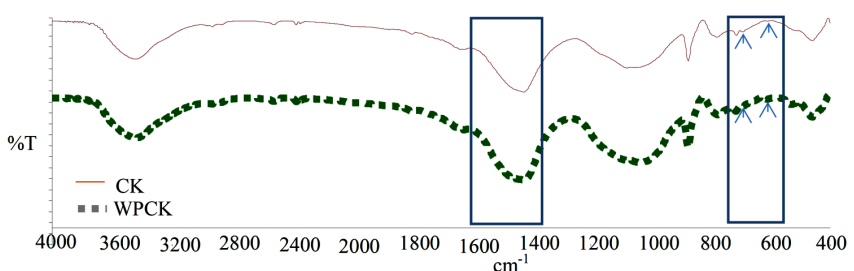

Fig. 1. FTIR spectrum of different paper reinforced concrete $\left(4000-400 \mathrm{~cm}^{-1}\right)$.

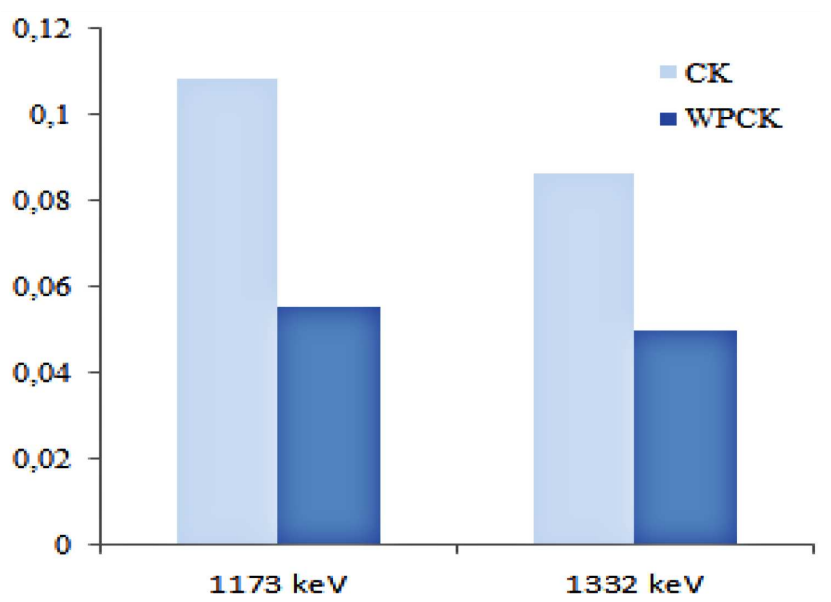

Fig. 2. Measured linear attenuation coefficients.

This indicates that the bond might be broken. It can also be said that this indicator can increase the fragility of the material.

The linear attenuation coefficients $(\mu)$ of WPCK and CK samples have been measured at the photon energies of at 1173 , and $1332 \mathrm{keV}$. The obtained results are displayed in Fig. 2. It can be seen that the measured results decrease with increase in photon energy, and among all energy levels WPCK have lowest attenuation coefficients.

\section{Conclusion}

Paper waste has been used as building material for decades, especially in cementation matrices and since then, a lot of research has been done to develop the mechanical properties of the composite like compressive, tensile, and flexural strength. Use of paper waste in structural concrete could become an economical and profitable substitute to landfills, incinerator etc. [9]. Samples densities CK and WPCK are $2.31 \mathrm{~g} / \mathrm{cm}^{3}$ and $1.68 \mathrm{~g} / \mathrm{cm}^{3}$, respectively. As the linear attenuation coefficients depend on the material density, it is interesting to plot obtained linear attenuation coefficients as a function of materials density [10].

\section{References}

[1] M.A. Nassar, N.A. Abdelwahab, N.R. Elhalawany, Carb. Polym. 76, 417 (2009).

[2] R.F.F. Meza, M.Sc. Thesis, Missouri University of Science and Technology, 2016.

[3] A. Samarin, En. Environ. Eng. 1, 90 (2013).

[4] S.R. Karade, L.K. Aggarwal, Met. Mater. Process. 17, 129 (2005).

[5] N. Stevulova, V. Hospodarova, J. Junak, Chem. Techn. 67, 30 (2016).

[6] İ. Akkurt, K. Günoğlu, C. Başyiğit, Ş. Kılıncarslan, A. Akkaş, SDU Int. Technol. Sci. 4, 135 (2012).

[7] P.J. Linstrom, W.G. Mallard, NIST Chemistry Webbook, NIST standard reference database No. 69, 2001.

[8] E. Tesser, Ph.D. Thesis, Università Ca'Foscari Venezia, 2014.

[9] L.R. Singh, A. Saleem, B. Geeta, Int. J. Eng. Res. Appl. 5, 95 (2015).

[10] İ. Akkurt, K. Günoğlu, C. Başyiğit. Ş. Kılınçarslan, A. Akkaş Acta Phys. Pol. A 123, 341 (2013). 